\title{
BUSCANDO GARANTIR OS DIREITOS DA CRIANÇA E DO ADOLESCENTE: RELATO DE EXPERIÊNCIA ${ }^{1}$
}

\author{
GUARANTEEING THE RIGHTS OF CHILDREN AND ADOLESCENTS: \\ REPORT ON AN EXPERIMENT \\ BUSCANDO GARANTIZAR LOS DERECHOS DEL NIÑO Y DEL \\ ADOLESCENTE: RELATO DE EXPERIENCIA.
}

\begin{abstract}
RESUMO: Este relato procura mostrar as ações desenvolvidas junto a familias, por uma equipe de profissionais na qual a enfermagem está inserida. Criança e familia mantêm relaçōes determinadas historicamente pelo contexto social ao qual se inserem, sendo que segundo a Pesquisa Nacional por Amostra de Domicilios, $53.5 \%$ das crianças e adolescentes brasileiros vivem em famílias com renda mensal per capita abaixo de meio salário minimo. As conseqüências da conjuntura econômica do pais atingem de forma bastante grave toda a população interferindo potencialmente nas questōes relacionadas às condiçōes de saúde da familia e consequentemente, da criança e do adolescente. Ao trabalharmos com a familia precisamos levar em consideraçăo o que a mesma pensa a respeito de suas funçōes, pois isso vai direcionar e/ou definir o papel que ela desempenha no seu cuidado, bem como no cuidado e proteçāo de cada um de seus membros, apesar de estar definido no Estatuto da Criança e do Adolescente, quais são as funçōes que se espera que ela desempenhe. O Projeto denominado "Casais de Apoio", conduzido por esta equipe leva em consideração as caracteristicas peculiares da familia, com o propósito de the oferecer suporte para que consiga cumprir os dispositivos legais no que tange ao cuidado da criança e do adolescente. Objetivamos com este trabalho divulgar o referido Projeto, bem como apontar a inserção do profissional enfermeiro em atividades diretamente relacionadas à promoção e manutenção da garantia dos direitos da criança e do adolescente, enquanto cidadãos inseridos no contexto familiar e social.
\end{abstract}

KEYWORDS: infância; familia; direitos; estatuto

\section{INTRODUÇÃO}

A inserção social da criança foi analisada por Orlandi(1985), Aries (1986), Gomes (1990) entre outros, os quais apontam como a sociedade a tem visualizado historicamente e como isso tem se traduzido em termos de práticas sociais voltadas para esse grupo populacional. $A$ análise feita pelos autores deixa claro que a criança e a familia mantêm relaçőes determinadas pelo contexto social no qual se inserem.

Os grandes contrastes caracterizados pela profunda diferenciaçăo espacial, tanto quantitativa quanto qualitativamente dos recursos de produção, de tecnologia e sobretudo da qualidade de vida, têm acompanhado a história do pais desde os tempos coloniais. O Brasil

${ }^{1}$ Trabalho apresentado na III Jomada de Enfermagem Pediátrica da UNICAMP, realizada nos dias 07 a 09 de Agosto de 1996.

${ }^{2}$ Enfermeira. Doutora em Enfermagem. Docente do Departamento de Enfermagem da Universidade Federal de Săo Carlos (UFSCar).

${ }^{3}$ Enfermeira. Doutoranda em Enfermagem Fundamental da Escola de Enfermagem de Ribeirão Preto - USP. 
inicia a década de 90 com um dos piores desempenhos entre os paises do terceiro mundo, no que diz respeito à pobreza e distribuiçăo de renda. Segundo a Pesquisa Nacional por Amostra de Domicilios, $53.5 \%$ das crianças e adolescentes brasileiros viviam em familias com renda mensal per capita abaixo de meio salário minimo, em 1990. A conjuntura econômica do país tem mostrado uma trágica combinaçăo entre estagnaçăo econômica e piora na distribuiçăo de renda. As consequeências dessa conjuntura atingem de forma bastante grave toda a população, interferindo potencialmente nas questőes relacionadas às condiçőes de saúde da família e consequentemente, da criança e adolescente (IBGE, 1992).

A criança, no processo de crescimento e desenvolvimento, em funçăo das características de ser imaturo e dependente, é submetida a relaçōes sociais definidas, que passam a expressar a forma pela qual a sociedade cuida dos corpos, das mentes e das consciências de acordo com sua inserção em classes sociais determinadas (Alvarenga, 1991).

Entendemos assim, que "cuidado à criança e ao adolescente" está direta e explicitamente relacionado ao cuidado da familia como um todo.

Ao abordarmos neste texto questões sobre criança, adolescente, saúde e familia, estaremos utilizando os seguintes conceitos:

CRIANÇA: "ser humano em processo de crescimento e desenvolvimento, sendo que esse processo interrelaciona-se e é determinado por inúmeros fatores biopsicosociaisespirituais" (Dupas, 1993).

De acordo com a Lei Federal $n^{\circ} 8.069$, de 13 de julho de 1990, Art. $2^{\circ}$ "é considerada criança a pessoa até doze anos de idade incompleto e adolescente aquela entre doze e dezoito anos de idade" (BRASIL, 1993).

ADOLESCENTE: "o ser humano quando passa por profundas transformaçōes, tanto a nível físico, como psicológico, o que acaba por modificar sua relaçăo com o mundo, já que esta 'nova pessoa' que está se reconfigurando, passa a ter significado diferente no mundo e este, por sua vez, passa a ser visto de uma forma diferenciada, adquirindo novas dimensões e possibilidades" (Vargas, Romeiro et al., 1992).

SAUUDE: "é a resultante das condições de alimentaçăo, habitaçăo, educação, renda, meio ambiente, trabalho, transporte, emprego, lazer, liberdade, acesso e posse da terra e acesso a serviços de saúde. É assim, antes de tudo, o resultado das formas de organizaçăo social da produção, às quais podem gerar grandes desigualdades nos niveis de vida" (CNS, 1987).

FAMILIA: "é um sistema interpessoal formado por pessoas que interagem por variados motivos, tais como afetividade e reprodução, dentro de um processo histórico de vida, mesmo sem habitar o mesmo espaço fisico. É uma relação social dinâmica que durante todo o seu processo de desenvolvimento assume formas, tarefas e sentidos elaborados a partir de um sistema de crenças, valores e normas, estruturados na cultura da familia, na classe social à qual pertence, em outras influências e determinaçōes do 'ambiente' em que vive, incluindo os valores e normas de outras culturas. Durante seu processo de viver, a dinâmica familiar apresenta mudanças representadas por aquelas esperadas no decorrer do desenvolvimento, e pelas mudanças situacionais ou acidentais, originadas no ambiente familiar e externo" (Patrício, 1994).

Elsen (1994) coloca que na vida diária quando falamos de familia năo nos parece necessário defini-la. Partimos do pressuposto de que todos têm em mente um significado idêntico, uma vez que a maioria de nós faz parte de uma comunidade familiar. Entretanto, cada um de nós possui uma visão particular do que é uma família, baseada na experiência vivenciada. É a maneira como cada um pensa a familia, mesmo sem uma teorização do seu conceito, que pode levar os individuos a conceber diferentes funçőes para a mesma.

Por isso trabalhar com familias é uma tarefa delicada e difícil, quando levamos em consideraçăo que o que a família pensa a respeito de sua funçăo direciona e/ou define o papel que ela desempenha no cuidado dela mesma, enquanto unidade familiar, bem como no cuidado 
e proteção de cada um de seus membros.

O Estatuto da Criança e do Adolescente - ECA (BRASIL, 1993) explicita os direitos dessa populaçăo e o que espera da familia, enquanto 'instituição' primeira gestora do cuidado de seus membros, como consta nos Artigos $3^{\circ}$ : "A criança e o adolescente gozam de todos os direitos fundamentais inerente à pessoa humana, sem prejuizo da proteçăo integral de que trata essa Lei, assegurando-se-lhes, por lei e por outros meios, todas as oportunidades e facilidades, a fim de Ihes facilitar o desenvolvimento fisico, mental, moral, espiritual e social, em condiçőes de liberdade e dignidade"; e $4^{\circ}$ : "É dever da familia, da comunidade, da sociedade em geral e do Poder Público, assegurar com absoluta prioridade, a efetivaçăo dos direitos referentes à vida, à saúde, à alimentação, à educaçăo, ao esporte, ao lazer, à profissionalização, à cultura, à dignidade, ao respeito, à liberdade e a convivência familiar e comunitária".

Ao instituir essa co-responsabilidade à comunidade, à sociedade em geral e ao poder público na efetivaçăo dos direitos citados, fica implicito que, quando a família năo estiver cumprindo sua função provedora e formadora, essas outras agências deverăo subsidiá-la, informando-a e instrumentando-a, excepcionalmente, afastando-a ou substituindo-a em algumas de suas funçőes (Szymanski, 1992).

O ECA prevê ainda a existência de duas instâncias responsáveis por assegurar que os direitos mencionados sejam garantidos, sendo Conselho dos Direitos da Criança e do Adolescente e Conselho Tutelar.

\section{CONSELHO DOS DIREITOS DA CRIANÇA E DO ADOLESCENTE E CONSELHO TUTELAR}

\section{LEGALIZAÇÃO DOS CONSELHOS}

O Estatuto da Criança e do Adolescente foi instituido pela Lei Federal $n^{\circ} 8.069$ de 1990 , substituindo o Código de Menores de 1979 e constitui uma ampla legislaçăo de defesa, proteçăo e desenvolvimento da criança e do adolescente. O ECA năo representa apenas uma declaraçăo de direitos, mas a força da lei, que institui mecanismos de exigibilidade. Săo normas que obrigam os responsáveis a cumprir suas determinaçøes, definindo sançס̋es ou puniçס̋es aos que as violarem e instâncias responsáveis pela garantia dos direitos da criança e do adolescente, que serão acionadas quando necessário, sendo elas, Conselho de Direitos, Conselho Tutelar, Ministério Público e Juizado da Infância e Juventude. Assim, o fato social e a norma jurídica podem integrar um conjunto de meios eficazes para o atendimento dos direitos e quando da sua violaçăo, podem acionar mecanismos de garantia para os deveres correspondentes. É preciso usar a lei como instrumento de sustentaçăo de decisões e açōes.

De acordo com a legislaçăo mencionada, toda a politica para o setor deverá ser elaborada pelos Conselhos dos Direitos da Criança e do Adolescente e executada pelos Conselhos Tutelares da Infância e Juventude.

Para viabilizar esta açăo co-participada, a Lei Federal $n^{\circ} 8.069$ prevê no Art. $88^{\circ}$, a criação dos Conselhos dos Direitos da Criança e do Adolescente em niveis federal, estadual, municipal, como órgăos compostos paritariamente por representantes governamentais e da sociedade civil, com funçőes deliberativas e de controle. O Conselho dos Direitos da Criança e do Adolescente tem um papel articulador político, com caráter deliberativo e deve controlar as ações públicas e privadas referentes à criança e ao adolescente.

O Art. $131^{\circ}$, versa sobre a criaçăo dos Conselhos Tutelares, de âmbito apenas municipal, composto por pessoas escolhidas democraticamente pela comunidade, encarregados de executar a política de promoçăo e defesa dos direitos da criança e do adolescente. O município pode criar quantos forem necessários, de acordo com a população, sendo que tem a obrigaçăo de ter pelo menos um. Em geral se propõe um Conselho Tutelar para cada 250.000 habitantes, mas a realidade vivida pela populaçăo infanto-juvenil no que se refere às situaçōes de risco, exploraçăo, 
violência, negligência é determinante para definir o número mínimo (Carvalho, 1993).

A atribuiçăo do Conselho Tutelar é intervir no nivel individual ou grupo afetado, enquanto a do Conselho dos Direitos é intervir no nível macro-social e da coletividade.

Assim, o Conselho Tutelar é importante termômetro da existência de problemas. A alta incidência de ocorrências individuais, denunciará os problemas que estão acontecendo; áreas de procedência; causas sociais dos mesmos etc, o que deverá ser encaminhado no nível de políticas pelo Conselho dos Direitos.

O Conselho Tutelar deve ser composto por cinco conselheiros, no mínimo, eleitos diretamente para uma mandato de três anos, por votação facultativa. Devem ter dedicação exclusiva e por isso, recebem um salário estabelecido pelo Conselho dos Direitos. A responsabilidade de seu funcionamento é da Prefeitura Municipal.

Os conselheiros têm como função o atendimento direto da menoridade. De acordo com o Art. $136^{\circ}$ do ECA, eles devem atender as crianças e adolescentes, atender e aconselhar os pais ou responsáveis, como também convocar pais, educadores, médicos, para serem advertidos ou orientados. Podem requisitar vagas em escolas, creches etc. Se não forem atendidos podem advertir essas pessoas como autoridade e, se ainda assim năo forem atendidos, podem encaminhar abertura de processo, inclusive penal, por desobediência. Podem também sugerir junto ao Conselho Municipal dos Direitos da Criança e do Adolescente, novas políticas a partir das demandas que detectarem.

Embora não haja relaçăo de subordinação entre eles, cabe ao Conselho dos Direitos a coordenaçăo do processo de escolha e implantaçăo do Conselho Tutelar.

\section{INSTALAÇÃO DOS CONSELHOS}

No municipio onde este estudo foi desenvolvido o Conselho Municipal dos Direitos da Criança e do Adolescente foi constituído em julho de 1991. O processo de instalação do Conselho Tutelar foi iniciado em janeiro de 1994, sendo definida uma comissão para seu planejamento e organizaçăo. A divulgaçăo sobre a seleçăo e eleição dos conselheiros, bem como o processo em si, ocorreram entre os meses de fevereiro e outubro de 1994. Em outubro do mesmo ano, foi realizada pelo Prefeito Municipal a nomeação das conselheiras eleitas e em novembro de 1994 tomaram posse na Câmara Municipal. Em dezembro de 1994, foram iniciadas as atividades do Conselho Tutelar do municipio.

\section{PROJETO “CASAIS DE APOIO”}

Em abril de 1995, após várias discussőes entre o Conselho Municipal dos Direitos da Criança e do Adolescente e o Conselho Tutelar sobre a questão de familias com dificuldades para o cumprimento de suas responsabilidades na função de provedora de seus membros, foi criada uma comissão para formular um plano de açăo que abrangesse tal população.

Havia um entendimento de que as familias têm direitos e não só deveres a serem cobertos pelo governo local e foi entăo deliberada pelo Conselho Municipal dos Direitos da Criança e do Adolescente a criação de um projeto denominado "Casais de Apoio". O propósito do projeto visava o acompanhamento e apoio às familias cujos filhos estavam sendo atendidos pelo Conselho Tutelar, objetivando ajudá-las a buscarem formas de reorganização interna e social.

A organizaçăo desse projeto foi realizada por membros da sociedade civil e pelo Conselho Municipal dos Direitos da Criança e do Adolescente. Uma vez estabelecidas as diretrizes que norteariam o projeto "Casais de Apoio", foi elaborado um folheto explicativo para a população, como o que segue. 


\section{CONSELHO TUTELAR DE SÃO CARLOS PROJETO: "CASAIS DE APOIO"}

O Conselho Tutelar e o grupo de voluntários que atuam no projeto "Casais de Apoio" vêm convidar a populaçăo em geral para conhecer e colaborar neste projeto.

O QUE É? - Trabalho de apoio ao Conselho Tutelar, visando acompanhamento e apoio às familias cujos filhos eståo sendo acompanhadas por este Conselho ou que se encontram abrigadas nas diversas Entidades do Municipio.

COMO FUNCIONA? - Trata-se de um trabalho não assistencialista, mas de promoçăo das familias alvo, através de visitas, orientaçōes, encaminhamentos, visando reestruturá-las, ajudando-as a assumir seu papel, particularmente junto aos filhos em situaçăo de risco.

QUEM PARTICIPA? - Podem participar casais e indivíduos que, voluntariamente, queiram dar sua contribuiçăo para tentar minimizar o quadro dos problemas sociais pelos quais passam familias, crianças e adolescentes, em decorrência de desestruturação econômica, social e moral.

COMO SE INSCREVER? Entrar em contato com o Conselho Tutelar: Rua Episcopal, 1323 Tel: 2741744 R 236, das 08:00 as 18:00h, de segunda à sexta-feira, onde receberão maiores esclarecimentos.

IMPORTANTE: As pessoas interessadas receberăo orientaçăo para o desempenho desse trabalho.

Uma ficha cadastral para que casais que tivessem interesse e disponibilidade pudessem se inscrever no projeto também foi distribuida para a comunidade.

Para a divulgação do projeto foram realizadas várias palestras em igrejas e outros segmentos da sociedade. Entretanto, a comissăo responsável pelo mesmo, percebeu que os casais interessados em participar apresentavam dificuldades em trabalhar junto às familias assistidas pois relatavam que nem sempre sentiam-se capazes de realizar uma abordagem adequada quanto aos problemas encontrados.

Baseada nessas dificuldades, a comissão responsável pelo projeto, procurou buscar a colaboração de profissionais que pudessem estar atuando em diferentes áreas, como facilitadores no atendimento às familias assistidas pelo Conselho Tutelar, constituindo assim uma "Equipe de Apoio Técnico" composta de profissionais das áreas de Enfermagem, Psicologia, Fonoaudiologia, Terapia Ocupacional e Fisioterapia, que começaram a atuar à partir de julho de 1995 junto ao projeto "Casais de Apoio".

Cada categoria profissional constituinte da equipe, elaborou uma proposta de assistência a ser executada junto às famílias atendidas pelo projeto, sendo que a uniăo das mesmas resultou na definiçăo de metas, metodologia de atendimento e formas de encaminhamentos a serem utilizadas junto a essas pessoas.

\section{ATUAÇÃO DO(A) ENFERMEIRO(A) JUNTO AO PROJETO "CASAIS DE APOIO"}

Mediante as necessidades relatadas pelo Conselho Tutelar e nossa possibilidade de atuação profissional, elaboramos como norteadores de nossa atuaçăo:

Objetivos:

1. Avaliar as condições de saúde da criança e da familia;

2. Orientar a familia sobre a importância de sua participaçăo na assistência à saúde da criança e de seus membros;

3. Identificar precocemente os processos patológicos favorecendo o diagnóstico e tratamentos oportunos; 
4. Realizar encaminhamentos para o atendimento em instituiçőes de saúde para crianças e/ou familiares quando necessário;

5. Acompanhar o desenvolvimento das ações propostas junto às familias.

\section{Formas de atendimento:}

Visita domiciliária: realizada conforme solicitação do Conselho Tutelar, de Casais de Apoio ou de outros profissionais da Equipe de Apoio Técnico.

Avaliação da criança e do adolescente: realizada durante a visita domiciliar, em instituição onde a criança se encontra abrigada, ou na sede do próprio Conselho Tutelar, quando detectado algum problema de saúde. É realizado um exame fisico, utilizando uma ficha elaborada pelas docentes da disciplina Enfermagem na Saúde da Criança, do Departamento de Enfermagem da UFSCar (Anexo 1).

Orientação: fornecer orientações para as familias assistidas pelo projeto, bem como aos Casais de Apoio de forma a viabilizar propostas para a resolução dos problemas detectados.

\section{METODOLOGIA DE TRABALHO DOS MEMBROS ENVOLVIDOS NO PROJETO}

A coordenadora do projeto, os membros da equipe de apoio técnico, os casais de apoio e a coordenadora das conselheiras se reúnem quinzenalmente para discussão dos casos sob atendimento, bem como dos novos casos.

Nessas reuniőes são avaliadas as ações que foram desenvolvidas por cada um dos membros presentes referentes a cada caso e săo estabelecidos planos de açăo mediante as necessidades apresentadas.

A atuação dos diferentes membros é direcionada ao alcance da meta primeira do projeto, ou seja, acompanhamento e apoio às familias para sua reestruturação enquanto unidade cuidadora de seus membros.

Os problemas denunciados ao Conselho Tutelar - uso de drogas, alcoolismo, maus tratos, abandono, prostituiçăo, ou seja, situações de risco para a criança e adolescente - são analisados e encaminhamentos são propostos na tentativa de viabilizar os meios necessários para possiveis soluçőes.

Assim, o que se pretende em tais reuniões é instrumentalizar o casal de apoio para que o mesmo possa atuar junto à família alvo.

Em situações onde a familia alvo năo consegue resolver seus problemas apesar dos vários caminhos apontados, das orientaçőes e ajuda, a mesma é convidada a participar das reuniões. Assim, busca-se oferecer mais uma oportunidade para que a familia possa apresentar os motivos pelos quais năo está conseguindo resolver seus problemas, apontando com isso, caminhos para a própria equipe. Isto faz com que a equipe se mobilize de forma a rever as ações anteriormente propostas e estabelecer novas formas de encaminhamentos.

Quando, apesar dessa dinâmica, não se consegue a reversão do quadro inicial de desestruturaçăo familiar e consequentemente a minimização da situação de risco para a criança e o adolescente, o caso é encaminhado ao Juizado da Infância e Juventude, acompanhado de um relatório que apresenta todas as ações realizadas, para que o mesmo tome as providências cabiveis.

Entretanto, vale ressaltar que esta medida só é tomada em última instância, visto que todos os membros envolvidos no projeto "Casais de Apoio" atuam com o interesse maior de manter a criança e o adolescente no contexto da unidade familiar. 


\title{
CONSIDERAÇŌES FINAIS
}

Muitas săo as dificuldades encontradas para garantir os direitos da criança e do adolescente previstos pelo Estatuto da Criança e do Adolescente, principalmente quanto ao Art $19^{\circ}$ - "Toda criança ou adolescente tem direito a ser criado e educado no seio de sua familia e, excepcionalmente, em familia substituta, assegurada a convivência familiar e comunitária, em ambiente livre da presença de pessoas dependentes de substâncias entorpecentes" -, num pais onde as desigualdades econômicas e problemas sociais năo recebem atençăo efetiva à nivel de Governo Federal, Estadual e Municipal.

Entendemos que uma das formas alternativas para se garantir tais direitos possa ser através da mobilização da sociedade para implementar projetos como esse aqui relatado. Tal projeto encontra vários obstáculos para seu desenvolvimento, principalmente no que tange à disponibilidade de casais que se proponham a serem "Casais de Apoio". Atualmente estão sendo realizadas reuniōes com membros da comunidade, lideres de movimentos de bairros, de pastorais, em locais da cidade de onde provêem um maior número de denúncias ao Conselho Tutelar, na tentativa de sensibilizar casais da própria comunidade a apoiarem famílias alvo, através da participaçăo no projeto.

Além da divulgaçăo do projeto Casais de Apoio, visto que năo se tem conhecimento de projeto similar na região, este relato objetiva apontar a inserçăo do profissional enfermeiro junto a atividades que buscam garantir os direitos da criança e adolescente enquanto cidadãos, inseridos no contexto familiar e social.

\begin{abstract}
This report discusses the nursing activities developed by a group of professionals within the family context. Children and their families maintain relationships determined historically by the social context within which they live. According to the National Survey by Address Sampling, $53.5 \%$ of Brazilian children and adolescents live in families whose monthly income per capita is under one half of a minimum salary. The consequences of the contry's recessive economy have a serious effect upon the entire population, potentially interfering in the family's health and, thus, in that of children and adolescents. When working with families we must consider what the family believes to be its function, since, despite the fact that the Children's and Adolescent's Statute gives the legal definition of family obligations, it is the family's beliefs that actually direct or define the role it plays in caring for and protecting each of its members. The "Support Couples" project, directed by this group, takes into consideration a family's particular characteristics so that it can offer support to the family to help it meet those legal requeriments related to child and adolescent care. The objective of this work is to divulge the Project itself, and to place professional nurses in activities that are directly related to the promotion and maintenance of children's and adolescent's rights as citizens inserted into a family and social context.
\end{abstract}

KEYWORDS: childhood, family, statute, rights

RESUMEN: Este relato procura enseñar las acciones desarrolladas junto a las familias, por un equipo de profesionales dentro del cual se insiere la enfermeria. El niño y la familia mantienen entre si relaciones determinadas, históricamente por el contexto social de su entoorno y según la "Pesquisa Nacional por Amostra de Domicilios", el 53.5\% de los niños y adolescentes brasileños viven en familias con renta mensual per capita inferior a la mitad del sueldo minimo. Las consecuencias de la estructura económica del pais se reflejan de forma muy grave en toda la población e interfieren potencialmente en todos los temas relacionados con la salud de la familia y, por supuesto, del niño y del adolescente. Al trabajar con la familia tenemos que llevar en consideración lo que ella misma piensa respecto a sus funciones, pues ello dirigirá y/o definirá el papel que desempeña en el cuidado, asi como en dicho cuidado y protección de cada uno de sus miembros, a pesar de que ya 
esta definido en el Estatuto del Niño y del Adolescente cuales son las funciones que de ella se esperan. El Proyecto denominado "Casais de Apoio"(Matrimonios/Parejas de Apoyo), que esta conducido por este equipo, lleva en consideración las caracteristicas peculiares de la familia, con el propósito de ofrecerle soporte para que consiga cumplir los dispositivos legales respecto al cuidado del niño y del adolescente. Se objetiva con el presente trabajo divulgar el referido Proyecto, asi como apuntar la inserción del profesional enfermero en actividades directamente relacionadas a la promoción y mantenimiento de la garantia de los derechos del niño y del adolescente, en tanto ciudadanos que forman parte de un contexto familiar y social.

PALABRAS CLAVE: infancia, familia, derechos, estatuto.

\section{REFERÊNCIAS BIBLIOGRÁFICAS}

ALVARENGA, A.T. Reflexões acerca da abordagem sociológica do crescimento e do desenvolvimento da criança no campo da saúde pública: aspectos teórico-metodológicos. Rev. Bras. Cresc. Des. Hum., v. 1, n. 2, p.51-64, 1991

ARIĖS, P. História social da criança e da familia. Tradução Dora Flaksman. 2. ed. Rio de Janeiro: Guanabara, 1986. 279p.

BRASIL. Ministério da Saúde. Estatuto da criança e do adolescente: lei federal n 8.069 de 13/07/ 90. Săo Carlos, Conselho Municipal dos Direitos da Criança e do Adolescente: UFSCAR, 1993. 59p.

CARVALHO, M.C.B. (Coord.) Trabalhando conselhos de direitos: estatuto da criança e do adolescente. São Paulo : PUC/IEE, 1993. 52 p. (Cadernos de Ação, 4)

CONFERÊNCIA NACIONAL DE SAÚDE, 8, Brasilia, 1986. Anais... Brasilia : Centro de Documentação do Ministério da Saúde, 1987. 430 p.

DUPAS, G. Politicas de saúde e assistência à criança. São Carlos, 1993. 22 p., (não publicado).

ELSEN, I. Desafios da enfermagem no cuidado de familias. In: BUB, L.I.R. (Coord.) et al. Marcos para a prática de enfermagem com familias. Florianópolis : Editora da UFSC, 1994. 195p. (Série Enfermagem - REPENSUL)

IBGE - FUNDAÇÃO INSTITUTO BRASILEIRO DE GEOGRAFIA E ESTATISTICA. Crianças e adolescentes: indicadores sociais. Rio de Janeiro : IBGE, 1992. v. 4

GOMES, F.Z., ADORNO, R.C.F. Crescimento e desenvolvimento na prática dos serviços de saúde. Revisăo histórica do conceito de criança. Rev. Saúde Pública, v. 24, n. 3, p.204-11, 1990

ORLANDI, O.V. Teoria e prática do amor à criança: introduçăo à pediatria social no Brasil. Rio de Janeiro : Zahar, 1985. 174 p.

PATRICIO, Z.M. Cenas e cenários de uma familia: a concretização de conceitos relacionados à situação de gravidez na adolescência. In: BUB, L.I.R. (Coord.) et al. Marcos para a prática de enfermagem com familias. Florianópolis : Editora da UFSC, 1994. 195p. (Série Enfermagem REPENSUL)

SZYMANSKI, H. Trabalhando com familias. São Paulo : PUC/IEE, 1992. 40 p. (Cadernos de Ação,1)

VARGAS, E.P.; ROMEIRO, E.A. (Coord.) et al. Práticas de educação em saúde - Programa de assistência integral à saúde da mulher. Rio de Janeiro : SDE/ENSP, 1992. $201 \mathrm{p}$. 


\section{UNIVERSIDADE FEDERAL DE SÃO CARLOS \\ DEPARTAMENTO DE ENFERMAGEM \\ FICHA DE EXAME FISICO}

Instituição:

$\mathrm{n}^{\circ}$ de matrícula:

Nome da criança:

Data de nascimento: / , /

Nome dos Pais:

01. APARÊNCIA GERAL (físico, nutricional, comportamento)

1.1. Estado emocional: alegria choro calma agitação apatia tristeza

1.2. Vestuário e calçado: Adequado à temperatura, ao ambiente, à atividade, limpeza. Data: ()()()()()() Data: ()()()()()() Data: ()()()()()()

02. DADOS ANTROPOMÉTRICOSE SINAIS VITAIS Peso Altura Pulso Respiração Temperatura Pressão Arterial Perimetro Torácico Perimetro Craniano

03. PELE: Integridade, coloraçăo, umidade, elasticidade, temperatura, manchas, pápulas, vesículas, turgor, pústulas, cicatriz, arranhöes, cortes, condições das unhas.

04. CABELO E COURO CABELUDO: Lesőes, piolho, lêndeas, prurido, condições de higiene, outros.

05. OLHOS: Tamanho, simetria, coloração, mobilidade, exame saco conjuntival, diâmetro das pupilas, (PIRRLA), estrabismo, ptose, irritaçăo, hipertelorismo, lacrimejamento, secreção, terçol, coloração de esclerótica, outros.

06. CABEÇA, FACE E PESCOÇO Simetria, fissura, fontanelas, mobilidade, expressão facial, gânglios (localização, dimensão e sensibilidade), controle da cabeça, outros.

07. NARIZ: Limpeza, odor, coriza, desvio de septo, secreção, epistaxe, obstrução, outros.

08. BOCA: Lábios (ressecamento, lesões), língua (cor, tamanho, freno, papilas), amígdalas (tamanho, secreção, coloração), odor, rouquidão, dentes (higiene, cárie, placa bacteriana, má oclusão), sangramento na gengiva, palato, outros.

09. OUVIDOS: Higiene, secreção (cor, odor), cerúmen (quantidade), otalgia, audição, condições do tímpano, outros.

10. TÓRAX: Formato, simetria, chiado, estertor, gânglios axilares, manchas, lesões, mamilos, ausculta cardiaca, outros.

11. ABDOMEM: Contorno, tensão, hérnias (umbilical e inguinal), massa palpável, outros. 
12. GENITÁLIA E ANUS: Masculina: escroto, períneo, higiene, prurido, edema, secreçăo, lesăo, dor, retraçăo do prepúcio, outros Feminina: conformaçăo, integridade (grandes e pequenos lábios, clitóris, meato urinário e vaginal, hímen), períneo, outros. Anus: Integridade, higiene, prurido, anormalidades.

13. DORSO E EXTREMIDADES: Coluna: depressăo, ondulaçăo, cistos, tufos de pêlos. Extremidades: simetria, dor, edema, lesőes, temperatura e coloraçăo, pé torto, pé plano, genu valgum (joelho para dentro, distância entre os maléolos $2.5 \mathrm{~cm}$ ), genu varum (joelho em arco, distância entre eles maior que $2.5 \mathrm{~cm}$ ), observar a marcha.

\section{CADERNETA DE VACINAÇÃO}

\section{DOSES}

Primeira

Segunda

Terceira

Primeiro Reforço

Segundo Reforço

\section{ANTI-POLIO D.P.T. B.C.G. SARAMPO OUTRAS}
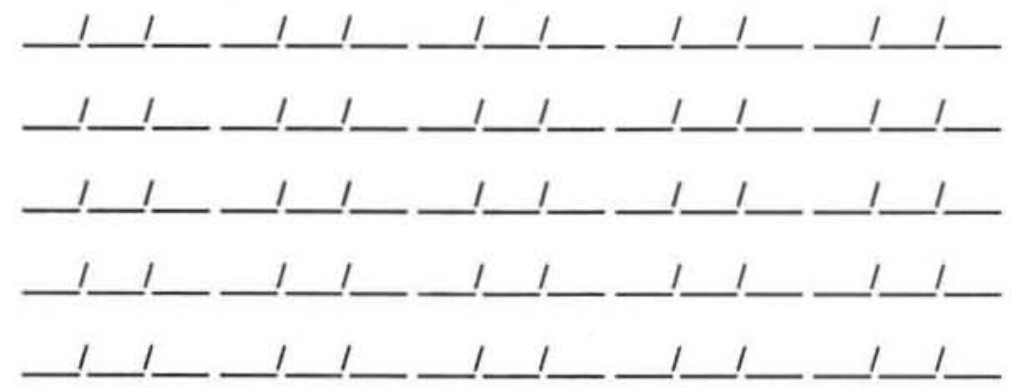